\title{
STUDIES IN ASYMPTOMATIC NEUROSYPHILIS
}

III. THE APPARENT INFLUENCE OF PREGNANCY ON THE INCIDENCE

OF NEUROSYPHILIS IN WOMEN *

JOSEPH EARLE MOORE, M.D.

BALTIMORE

In the second paper of this series ${ }^{1}$ it was pointed out that in spite of the fact that clinical neurosyphilis is more common in men than in women, cytobiologic abnormalities in the cerebrospinal fluid of primary and secondary syphilitics are equally frequent in the two sexes. Futhermore, evidence was presented to show that from the group of patients showing these early fluid abnormalities (early asymptomatic neurosyphilis) arise most, if not all, of the late cases of clinical meningeal and parenchymatous neurosyphilis. Since women are comparatively exempt from clinical neurosyphilis, there must be some special factor, applying only to the female sex, which inhibits its development. It was suggested that pregnancy might be the factor in question. The purpose of this paper is to examine this point more in Cetail.

The literature is replete with statistics, dating from the earliest days of the study of syphilis, regarding the comparative incidence of neurosyphilis in the two sexes. The most complete are those recently published by Gärtner ${ }^{2}$ on general paresis. He finds, on the basis of the incidence of paresis over a period of years in a population of about $38,000,000$ Germans, that the ratio of paretic men to women is $3.43: 1$. Gärtner and other authors, notably Fournier, ${ }^{3}$ suggest that this difference is largely due to the higher incidence of syphilis in men than in women, together with extraneous factors such as the greater stress of masculine activities.

Virtually, all women with acquired syphilis are within the child bearing period and are thus subject to any influence which pregnancy

* From the Syphilis Department of the Medical Clinic, Johns Hopkins Hospital.

* This clinical research has been aided by grants from the United States Interdepartmental Social Hygiene Board and from the American Social Hygiene Association.

1. Moore, J. E.: Studies in Asymptomatic Neurosyphilis. II. The Classification, Treatment, and Prognosis of Early Asymptomatic Neurosyphilis, Bull. Johns Hopkins Hosp. 33:231 (July) 1922.

2. Gärtner, W.: Ueber die Häufigkeit der progressiven Paralyse bei kultivierten und unkultivierten Völkern. Eine statistische, biologische, und Immunitätsuntersuchung über die Syphilis, Ztschr. f. Hyg. u. Infektionskr. 92: 341 (July) 1921.

3. Fournier, A.: Les Affections Parasyphilitiques, Rueff et Cie, Paris, 1894, p. 168 et seq. 
may exert. Congenital neurosyphilis, however, for example, juvenile paresis, develops in most instances before the child bearing age. In this condition, according to statistics gathered by Schmidt-Kraepelin, both sexes are about equally affected, with only a slight preponderance of males.

Statistical data from the Syphilis Clinic of the Johns Hopkins Hospital are available for the examination of this problem. The clinic is for charity patients only. Its clientele is almost equally divided between the white and colored races. As to sex, there are about equal numbers of white and colored males, but colored females predominate over white women in the ratio of about $3: 2$. This racial distribution must be taken into consideration in connection with the percentage data given for the sex incidence of neurosyphilis. The comparative freedom of negroes from neurosyphilis ${ }^{5}$ tends to distort the percentages somewhat in favor of the female sex. For the purpose of the present discussion, however, the question of race has been disregarded, since

Table 1.-The Incinence According to Sex of Various Types of Syphilis, and Fspectally Neurosiphulis, Based on the Admission

Diaginosies of 5,410 SyphintTic Pathents

\begin{tabular}{|c|c|c|c|c|c|c|}
\hline & & \multicolumn{2}{|c|}{$\overbrace{}^{\text {Male }}$} & \multicolumn{3}{|c|}{ Female } \\
\hline & $\begin{array}{ll}\text { Dumber } & \text { Numosis } \\
\text { of Cases }\end{array}$ & \multicolumn{2}{|c|}{$\begin{array}{l}\text { Per Cent. of } \\
\text { Iotal Males }\end{array}$} & $\begin{array}{l}\text { Number } \\
\text { of Cases }\end{array}$ & \multicolumn{2}{|c|}{$\begin{array}{l}\text { Per Cent. of } \\
\text { Total Females }\end{array}$} \\
\hline \multirow{2}{*}{\multicolumn{2}{|c|}{ 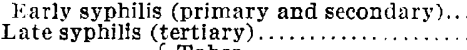 }} & \multirow{2}{*}{\multicolumn{2}{|c|}{$\begin{array}{l}36.60 \\
24.29\end{array}$}} & 604 & \multirow{2}{*}{\multicolumn{2}{|c|}{$\begin{array}{l}24.77 \\
26.37\end{array}$}} \\
\hline & & & & 643 & & \\
\hline & Tabes.................... 140 & $4 . ; 1$ & \multirow{3}{*}{20.38} & 22 & 0.90 & \multirow{4}{*}{6.47} \\
\hline \multirow{3}{*}{ Neurosyphilis } & $\begin{array}{l}\text { General paresis........... } \\
\text { Meningeal................ }\end{array}$ & $\begin{array}{l}6.96 \\
1.68\end{array}$ & & $\begin{array}{l}49 \\
22\end{array}$ & $\begin{array}{l}2.01 \\
0.90\end{array}$ & \\
\hline & Vascular.................... & 1.11 & & 7 & 0.28 & \\
\hline & Unclassifled............... & 5.88 & & 58 & 2.37 & \\
\hline \multicolumn{2}{|c|}{ 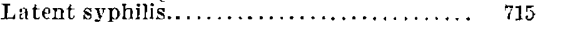 } & \multicolumn{2}{|c|}{24.06} & 1,130 & \multicolumn{2}{|c|}{47.57} \\
\hline
\end{tabular}

both whites and blacks are subject alike to the factor of pregnancy. The social level of these patients needs little explanation. For the most part, they are unskilled laborers and their families.

Reference to Table 1 shows that of 5,410 patients with syphilis, 54 per cent. are males, 46 per cent. females. There is, thus, no great preponderance of syphilis in men in this class of patients. In order to emphasize the influence of pregnancy on the disease, all admission diagnoses have been tabulated. Marked sex variations are apparent in three of the four groups. The lower percentage of females with early syphilis is partly due to the anatomic difference in the sexes, with the consequent difficulty of detection of primary syphilis in the female. (Secondary syphilis is about equally frequent in the two sexes: 22.9

4. Schmidt-Kraepelin, T.: Ueber die Juvenile Paralyse, Monogr. a. d. Gesamtgebiete d. Neurol. u. Psychiat., Julius Springer, Berlin 20: 1920.

5. Zimmerman, E. L.: A. Comparative Study of Syphilis in Whites and Negroes, Arch. Dermat. \& Syph. 4:75 (July) 1921. 
per cent. males as against 21.5 per cent. females). No sex variation is evident in the incidence of tertiary syphilis. Latent syphilis, however, is twice as frequent in women as in men. This striking difference is due, together with part of the variation in the incidence of primary syphilis, to the effect of pregnancy on the course of the disease. No less than 470 , or 42 per cent., of the women with latent syphilis, were pregnant on admission to the clinic.

The fact that women who bear syphilitic children often give no history of syphilis and present no signs of the disease (except a positive blood Wassermann reaction) has long been common knowledge. A study of the pregnant women in this clinic, now in progress, has convinced us that the usual early manifestations of syphilis are markedly altered by the occurrence of pregnancy. A woman infected at or shortly after the time of conception usually does not develop a chancre or secondary syphilis. When infection takes place late in pregnancy, on the other hand, the usual course of events may follow, but is often much delayed. Substantiation of these clinical data in experimental syphilis is furnished by the recent work of Brown and Pearce. ${ }^{6}$

If such striking alterations in the early course of the disease can be caused by a concurrent pregnancy, it is of great interest to examine the later course of syphilitic women who have been pregnant as contrasted with those in whom no pregnancy has occurred since infection. In the preceding paper of this series, it was shown that the incidence of spinal fluid abnormalities in 113 women with primary or secondary syphilis (examination of the fluid having been carried out, in most instances, within the first two years of the disease) was 22.1 per cent., as compared with 21.6 per cent. in a similar group of 217 men. None of these women were pregnant at the time of infection, and all had passed through the usual course of early syphilis. This is a satisfactory demonstration that in the early stages of the disease, when pregnancy can be excluded as a modifying factor, the nervous systems of both sexes are equally liable to invasion by the organism. In orcler to determine, therefore, the possible influence of pregnancy, late syphilis only (of more than one year's duration) should be chosen. There must be contrasted the incidence of clinical neurosyphilis and of spinal fluid abnormalities, first in women as compared with men, and second in a group of women who were pregnant at or since infection as compared with a group who have had no pregnancies.

In Table 1 it is shown that 20.38 per cent. of the cases in males were diagnosed as being clinically neurosyphilitic on admission, as

6. Brown, W. H. and Pearce, L.: On the Reaction of Pregnant and Lactating Females to Inoculation with Treponema Pallidum; A Preliminary Note, Am. J. Syph. 4:593 (Oct.) 1920. 
compared with only 6.47 per cent. of the females. For every case of neurosyphilis in the female, therefore, there are 3.13 cases in the male. Further analysis shows the following ratios:

Cerebrospinal syphilis (unclassed)..for 1 female, there are 2.48 males

Tabes dorsalis ............... for 1 female, there are 6.36 males

General paresis ..............for 1 female, there are 4.22 males

Meningeal neurosyphilis ......... for 1 female, there are 2.27 males

Vascular neurosyphilis .......... for 1 female, there are 4.71 males

These figures are more accurate than those usually given, since they are based on the total number of male and female patients with syphilis, rather than on neurosyphilitics only. With regard to the proportion of pregnant and nonpregnant females, data regarding this series are not available. Junius and Arndt, ${ }^{\top}$ however, to mention only one of many articles dealing with this point, state that from 47 to 49 per cent. of paretic women are sterile, as compared to 16 or 20 per cent. of childless women in the general population. These authors,

Table 2.-The Incidence of Spinal Fluid Abnormalities in Late Syphilis Without Evidence of Neurologic Damage: A Comparison of Men AND WoMen

\begin{tabular}{|c|c|c|c|c|c|c|}
\hline \multirow[b]{2}{*}{ Diagnosis } & \multicolumn{3}{|c|}{ Male } & \multicolumn{3}{|c|}{ Female } \\
\hline & $\begin{array}{l}\text { Total } \\
\text { Cases }\end{array}$ & $\begin{array}{c}\text { Abnormal } \\
\text { Fluids }\end{array}$ & $\begin{array}{l}\text { Per Cent. } \\
\text { Abnormal }\end{array}$ & $\begin{array}{l}\text { Total } \\
\text { Cases }\end{array}$ & $\begin{array}{c}\text { Abnormal } \\
\text { Flujds }\end{array}$ & $\begin{array}{l}\text { Per Cent. } \\
\text { Abnormal }\end{array}$ \\
\hline IT. Recurrent........... & 8 & 2 & 25.0 & 4 & - & 0.0 \\
\hline II. Late............... & 2 & - & 一 & 1 & 一 & - \\
\hline $\begin{array}{l}\text { III. Skin and mueous } \\
\text { membrane.......... }\end{array}$ & & & & & & \\
\hline 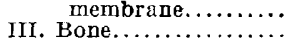 & 30 & 8 & 26.6 & 39 & 3 & 7.8 \\
\hline III. Bone.............. & 40 & 5 & 20.0 & 31 & 4 & 12.8 \\
\hline III. Cardiovascular...... & 38 & 7 & 18.4 & 10 & 2 & 20.0 \\
\hline III. Visceral............ & 14 & 4 & 28.5 & 17 & - & - \\
\hline 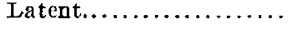 & 177 & 39 & 22.0 & 131 & 29 & 22.1 \\
\hline Total............... & 309 & 65 & 21.03 & 233 & 38 & 16.3 \\
\hline
\end{tabular}

and others, have all dealt with the subject from the standpoint of the influence of syphilis on child bearing, to show that syphilis causes sterility. So far as I am aware, it has not been suggested heretofore that pregnancy may alter the incidence of neurosyphilis in women, and that about half the paretic females may be paretic because of their sterility.

A further important point is the incidence of abnormal spinal fluids in late syphilitics without demonstrable neurologic abnormalities. For examination of this question 542 patients from this clinic are available. It is shown in Table 2 that of 309 men, 21.03 per cent. had abnormal fluids, as compared with 16.3 per cent. fluid abnormalities in 233 women. The percentage of abnormal spinal fluids in late syphilis of males is almost the same as the percentage in early syphilis (21.03 as

7. Junius, P., and Arndt, M.: Ueber die Deszendenz der Paralytiker, Ztschr. f. d. Ges. Neurol. u. Psychiat. 17:303, 1913. 
compared with 22.9). In women, on the contrary, spinal fluid changes are less frequent in late than in early syphilis ( 16.3 per cent. as compared with 22.1 per cent.).

If pregnancy is a factor of importance in causing this lowered incidence, those women with late syphilis who have been pregnant since their infection should show a lower proportion of abnormal fluids than those who have never been pregnant. That this is actually the case is shown in Table 3. Of ninety late syphilitic women who had never been pregnant, or had borne children only before infection with syphilis, 22.2 per cent. had abnormal fiuids, while of 142 cases in which pregnancy had occurred one or more times after infection, only 11.2 per cent. were thus abnormal. The same phenomenon is observed whether tertiary manifestations of syphilis were present, or whether the disease was latent. The proportion of spinal fluid abnormalities in late syphilis, when no pregnancies have occurred, is thus precisely the same as that observed in early syphilis. In pregnant women, this percentage is reduced by one half.

TABLE 3.-The Comparative Incidence of Late Asymptomatic Neurosyphilis in Women, Showing the Effect of Pregnancy on the Disease

\begin{tabular}{|c|c|c|c|c|c|c|}
\hline \multirow[b]{2}{*}{ Diagnosis } & \multicolumn{3}{|c|}{$\begin{array}{c}\text { Syphilis Contraeted at Conception } \\
\text { or Pregnant Since Infection }\end{array}$} & \multicolumn{3}{|c|}{ Never Pregnant Since Infection } \\
\hline & $\begin{array}{l}\text { Total } \\
\text { Cases }\end{array}$ & $\underset{\text { Fluids }}{\text { Abnormal }}$ & $\begin{array}{l}\text { Per Cent. } \\
\text { Abnormal }\end{array}$ & $\begin{array}{l}\text { Total } \\
\text { Cases }\end{array}$ & $\begin{array}{l}\text { Abnormal } \\
\text { Fluids }\end{array}$ & $\begin{array}{l}\text { Per Cent, } \\
\text { Abnormal }\end{array}$ \\
\hline 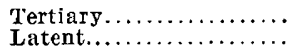 & $\begin{array}{l}54 \\
89\end{array}$ & $\begin{array}{r}2 \\
14\end{array}$ & $\begin{array}{r}3.7 \\
15.6\end{array}$ & $\begin{array}{l}44 \\
46\end{array}$ & $\begin{array}{r}7 \\
13\end{array}$ & $\begin{array}{l}15.9 \\
28.2\end{array}$ \\
\hline Total............. & 143 & 16 & 11.2 & 90 & 20 & 22.2 \\
\hline
\end{tabular}

Included in the "pregnant" group are a considerable number of cases of conceptional syphilis-that is, infection with syphilis simultaneously with conception, and with consequent suppression of the early lesions of the disease. Thus a history of primary or secondary syphilis was obtained in only 21.8 per cent. of the patients in this group, as contrasted with 53.4 per cent. in the "never pregnant" group of women, and with 85.5 per cent. of males.

When infection with syphilis and pregnancy occur simultaneously, there can be no doubt that some factor in connection with the pregnancy inhibits the development of grave syphilitic lesions. This being so, one may ask if pregnancies occurring some time after infection confer the same sort of protection, and whether repeated pregnancies protect even more than a single one. As regards the former of these points, no information is at present available. In Table 4 is shown the percentage of abnormal spinal fluids in women who had had from one to five or more pregnancies since infection. There would seem to be 
some protective influence exerted by repeated pregnancy, though the statistics are based on too small numbers and are, therefore, too irregular to be of much value. However, the percentage of abnormal fluids in those women who had two or more pregnancies is only 9.3 , as compared with 19.5 in primiparae.

TABLE 4.-The Incidence of Late Aysmptomatic Neurosyphilis in Women, Grouped According to the Number of Pregnancies Since Infection

\begin{tabular}{|c|c|c|c|}
\hline Number of Pregnancies & $\begin{array}{l}\text { Total } \\
\text { Cases }\end{array}$ & $\begin{array}{l}\text { Abnormal } \\
\text { Spinal Fluid }\end{array}$ & $\begin{array}{l}\text { Per Cent. } \\
\text { Abnormal }\end{array}$ \\
\hline 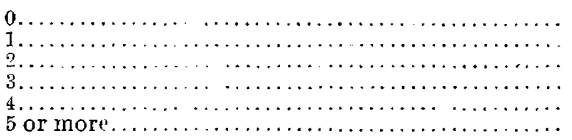 & $\begin{array}{l}90 \\
41 \\
36 \\
20 \\
21 \\
19\end{array}$ & $\begin{array}{r}20 \\
8 \\
3 \\
3 \\
1 \\
2\end{array}$ & $\begin{array}{r}22.2 \\
19.5 \\
8.3 \\
15.0 \\
4.7 \\
10.5\end{array}$ \\
\hline
\end{tabular}

It is not suggested that pregnancy occurring some time after infection, the woman having passed through the usual course of early syphilis, may exert any influence on the subsequent development of neurosyphilis. A larger series of cases than the present one is needed for examination of this point. Nor does the silent course of conceptional syphilis protect absolutely against later neurosyphilis. It is a well established clinical fact that in males, a mild early syphilis predisposes to neurosyphilis, possibly because of some alteration in the immune reactions of the body. In women, on the contrary, the factor of pregnancy in some way alters the defense mechanism so that the absence of early syphilitic lesions does not render the nervous system more susceptible to invasion. In this series, for example, spinal fluid abnormalities were present in 20.4 per cent. of eighty-three women, who, regardless of pregnancy, gave a definite history of primary or secondary syphilis, while of 161 women in whom such a history could not be obtained, only 13 per cent. had abnormal fluids.

\section{CONCLUSIONS}

1. Clinical neurosyphilis is about three times as frequent in men as in women.

2. The nervous systems of the two sexes are, however, invaded with equal frequency in the early stages of syphilis, as is shown by the relative percentages of spinal fluid abnormalities.

3. The course of early syphilis is markedly altered by the simultaneous occurrence of pregnancy.

4. Pregnancy is the most important point of difference in the ordinary life history of the two sexes. 
5. In women with late syphilis (of more than one year's duration), the incidence of abnormal spinal fluids is twice as high in a group of sterile women as in a group in which one or more pregnancies have occurred since infection.

6. Almost half of the women who are clinically neurosyphilitic have not been pregnant since infection.

7. Multiparae seem to be less liable to late asymptomatic neurosyphilis than primiparae.

8. It is suggested on the basis of this study that pregnancy is one factor which may partially account for the comparative freedom of women from neurosyphilis. 